\title{
Avaliação de processos nas linhas de beneficiamento e classificação de batatas
}

\author{
Marcos David Ferreira' ${ }^{1}$ Luiz Henrique Netto ${ }^{2}$ \\ ${ }^{1}$ UNICAMP/FEAGRI, C. Postal 6011, 13083-875 Campinas-SP; ${ }^{2}$ UNICAMP/FEA, C. Postal 6121, 13083-862 Campinas-SP; \\ marcos.ferreira@agr.unicamp.br.
}

\section{RESUMO}

A batata é uma das principais hortaliças cultivadas no Brasil, sendo uma cultura de grande expressão econômica no estado de São Paulo. Após a colheita os tubérculos são submetidos aos processos de beneficiamento e classificação, sendo então destinados ao mercado consumidor. Neste trabalho realizou-se a descrição e a caracterização dos processos das unidades de beneficiamento e classificação de batatas por meio da identificação do material usado para a construção do maquinário, caracterização dimensional dos equipamentos, medidas de rotação de operação das esteiras de abastecimento e das classificadoras, determinação da velocidade de deslocamento e da rotação dos tubérculos e a produtividade dos operários. Determinou-se também os pontos críticos de impacto com queda durante o beneficiamento, utilizando-se a esfera instrumentada (70 $\mathrm{mm}$ ), Techmark, Inc., Lansing, Michigan, Estados Unidos. Com esta, obtiveram-se dados de aceleração máxima (G) e mudanças na velocidade $(\Delta v)$. Este levantamento foi realizado em cinco unidades de beneficiamento e classificação para batatas localizadas no estado de São Paulo. Observou-se variação quanto ao comprimento do equipamento, atingindo $26,5 \%$. Foi constatado também variação na vazão de água entre as unidades devido à diferença nos sistemas utilizados para a lavagem dos tubérculos, tendo os volumes oscilado de 15,4 a 168 mil litros por hora. As escovas mais utilizadas na etapa de lavagem eram compostas de cerdas com nylon cristal e fibra de coco, não sendo encontradas escovas compostas de origem animal. A rotação média para todas as unidades na etapa de lavagem foi de 157 rpm, porém verificou-se variação de $75 \%$ (112 a $196 \mathrm{rpm}$ ). Para a etapa de secagem, a rotação média foi de $122 \mathrm{rpm}$, tendo oscilado de 68 a $210 \mathrm{rpm}$. Os pontos das linhas de beneficiamento e classificação de batata demonstraram maior $\mathrm{G}$ nos pontos de transferência (entrada do lavador e ensaque). Nas unidades A, B e D as maiores médias de $\mathrm{G}$ ocorreram nas etapas iniciais de lavagem, apresentando valores próximos de $140 \mathrm{G}\left(\mathrm{m} / \mathrm{s}^{2}\right)$.

Palavras-chave: Solanum tuberosum L., beneficiamento, lavadora, esfera Instrumentada e qualidade de tubérculos.

\begin{abstract}
Process evaluation on potato packing lines

Potatoes are one of the most important vegetable crops in Brazil, and are especially important in São Paulo State. After harvesting, potatoes are sorted and classified in a packinghouse, then shipped to consumers. The goal of this research was to describe the main features and working systems used in a potato packing line. Therefore, the material type used was identified taking into account the dimensions of the equipments, brushes rotation on receiving belts and sorting lines, average velocity, tuber displacement velocity and rotation, and employee daily yield. The critical points for drop impact were measured using an instrumented sphere $(70 \mathrm{~mm})$, Techmark, Inc. Lansing, Michigan, USA. Results for maximum Acceleration (G) and velocity changes $(\Delta v)$ were found. This research was done in five packinghouses of São Paulo State. A variation occurred in length among the lines, of about $26,5 \%$. The water consuption varied among the units based on the washing system used, and volume dispended varied from 15,4 to 168 thousand liters/hour. The main brushing composition used on the washing brushes were nylon and coconut fiber, and brushes of animal origin were not used. The average rotation observed on the washing step was $157 \mathrm{ppm}$, with a variation of $75 \%$ (112-196 rpm). For the drying step, the average rotation was 122 rpm, varying from 68 to $210 \mathrm{rpm}$. The critical points that showed high $\mathrm{G}$ were the transfer points (washing entrance and packing). At units $\mathrm{A}, \mathrm{B}$ and $\mathrm{C}$ the high $\mathrm{G}$ values were at the initial washing steps, closely to $140 \mathrm{G}\left(\mathrm{m} / \mathrm{s}^{2}\right)$.
\end{abstract}

Keywords: Solanum tuberosum L, sorting, packing line washer, instrumented sphere, tuber quality.

\section{(Recebido para publicação em 18 de março de 2006; aceito em 30 de março de 2007)}

\begin{abstract}
A batata é uma das hortaliças de grande expressão econômica no Brasil, sendo depois do trigo, arroz e milho, a maior em produção. No Brasil em 2003 a produção total de batatas foi de 3,05 milhões de toneladas (IBGE citado por FNP-Consultoria \& Comercio, 2005). As regiões Sul e Sudeste são as principais produtoras brasileiras de batata. Os estados de MG, PR, SP, RS e $\mathrm{SC}$ respondem em conjunto por $96 \%$ da produção brasileira, sendo que Minas
\end{abstract}

Gerais ocupa a liderança nacional em produção e produtividade (Resende $e t$ al., 1999).

A produção total de batata corresponde aproximadamente ao consumo nacional, sendo que cerca de $95 \%$ são consumidas "in natura", e os 5\% restantes na forma industrializada como pré-fritas congeladas, chips e pré-cozidas (FNP-Consultoria \& Comercio, 2005). Quase a totalidade da batata consumida in natura é lavada, sendo este procedimento exigido pelo consumidor.

No Brasil duas alternativas têm sido utilizadas para beneficiamento e classificação da batata após a colheita. $\mathrm{Na}$ primeira alternativa, mais simples e pouco utilizada, a batata é arrancada e exposta na superfície do solo por algumas horas para secagem ou perda da água superficial. Em seguida passa por processo de seleção e classificação manual no campo. Logo após, é ensacada, colo- 
cada em caminhões e transportada até os pontos de venda. Na segunda alternativa, a batata recém colhida é levada para galpões onde, sofre uma lavagem e secagem. Após é selecionada, classificada manualmente e/ou mecanicamente e ensacada. Depois de ensacada pode ser armazenada e transportada conforme a demanda do mercado (Finger \& Fontes, 1999) ou enviada imediatamente aos pontos de venda, o que é mais comum.

A conservação da batata, após a colheita, dependerá em grande parte da maturidade fisiológica do tubérculo. A periderme do tubérculo imaturo é pouco resistente e as paredes celulares, são mais finas que em tubérculo maduro. Isso pode aumentar a incidência de danos nos tubérculos colhidos imaturos (Finger \& Fontes, 1999). Após o arranquio dos tubérculos no campo, a quantidade total do produto é reduzida até chegar ao consumidor. Ocorrem perdas na própria colheita, no beneficiamento, no transporte, nos pontos de venda do atacado e do varejo e também no consumo, principalmente pelo armazenamento inadequado dos tubérculos. Durante a secagem inicial em campo, já ocorre perda de peso. Em seguida, no beneficiamento, ocorre o descarte de solo aderido aos tubérculos, assim como o descarte da batata nãocomercial, ou seja, tubérculos com defeitos graves detectados visualmente e eliminados manualmente. A lavagem dos tubérculos, apesar de ser prática predominante, é questionável, pois pode acentuar os seus defeitos e ainda tornálos mais suscetíveis à deterioração, além de aumentar a porcentagem de descarte (Finger \& Fontes, 1999). Henz \& Brune (2004) relatam que as perdas póscolheita para batata avaliadas em estudo em Brasília (DF) foram 10,3\% para a batata não lavada e $93 \%$ para a batata lavada, constatando, portanto que o processo de lavagem aumenta a incidência de deterioração.

As alterações na batata durante o processo da colheita até o consumo são principalmente do tipo mecânica, fisiológica ou patológica. Danos mecânicos ocorrem durante o manuseio dos tubérculos (colheita, seleção, embalagem, transporte e exposição). Danos fisioló- gicos e patológicos se dão principalmente, na fase de produção, transporte e exposição.

Danos mecânicos devidos a impactos, compressão, vibração, cortes e rachaduras estão relacionadas com alterações fisiológicas, metabólicas, de aroma, sabor e qualidade em diferentes produtos hortícolas tais como maçãs, pepinos, batatas e tomates (Moretti \& Sargent, 2000). O dano mecânico pode ser ocasionado por uma pequena força, pressão, e por impacto em uma superfície dura (Mohsenin, 1970).

A incidência e a severidade da desordem fisiológica dependem da energia e do número de impactos e do estádio de amadurecimento. Ela é cumulativa durante as práticas de manuseio póscolheita (Sargent et al., 1992b). Portanto, as várias etapas de manuseio do produto, desde o campo até o consumidor, devem ser cuidadosamente coordenadas e integradas para maximizar a qualidade do produto (Sargent et al, 1992a). Em geral, danos por impacto na pós-colheita podem ocorrer quando os frutos recebem quedas altas ou colidem com superfícies não protegidas ou com outros frutos. A severidade dos danos causados por impactos em uma linha de classificação pode ser reduzida diminuindose a altura de elevação de queda entre as etapas ou através da utilização de protetores, os quais podem dissipar a força de impacto. O número de impactos também pode ser reduzido diminuindo o número de quedas e de pontos de transferência em uma linha de classificação (Hyde \& Zhang, 1992). Para redução na força de impacto e danos físicos em uma linha de beneficiamento e classificação estas devem ser projetadas preferencialmente em uma linha reta, sem desvios e curvas, e possuir alturas mínimas entre as etapas (Sargent et al., 1999).

Jobling (2000) relatou que as perdas devido a impacto e danos físicos em batata podem chegar até $40 \%$ na póscolheita, influenciando diretamente no aumento da incidência de doenças. As principais doenças associadas aos danos físicos em batatas são podridões bacterianas (Henz \& Brune, 2004). Lesões externas caracterizam-se pela descoloração da superfície danificada, causada pelo aumento da pigmentação pro- duzida, proporcionando a superfície impactada o escurecimento (Expido et al., 2005).

O objetivo deste trabalho foi a caracterização dos processos de beneficiamento e classificação de batatas e a determinação de pontos críticos de impacto.

\section{MATERIAL E MÉTODOS}

Os dados foram coletados em cinco unidades de beneficiamento e classificação de batatas no estado de São Paulo, localizados nos municípios de Vargem Grande do Sul (Unidades A, B e C), Itapetininga, (Unidade D) e Divinolândia (Unidade E).

Nos equipamentos de classificação e beneficiamento de batatas foram observados os materiais utilizados na construção dos equipamentos. Para a caracterização dimensional do tipo de classificadora utilizada foram feitas medidas com o auxílio de uma trena profissional. Foi mensurada cada fase do equipamento, aferindo-se tanto o comprimento quanto as larguras interna e externa. Mediram-se as alturas de cada queda sofrida pelos tubérculos ao longo do percurso no equipamento. Tomouse cada medida perpendicularmente, desde o local exato de contato após a queda até o ponto de onde o tubérculo iniciava a mesma. Dimensionou-se, ainda, o tamanho das grades de seleção com auxílio de régua milimetrada.

$\mathrm{Na}$ avaliação da velocidade de operação das esteiras de abastecimento e das classificadoras mensurou-se o comprimento das esteiras das cinco unidades, calculando-se o tempo médio para funcionamento do equipamento. Para mensuração da velocidade de deslocamento do tubérculo na etapa de lavagem um tubérculo, marcado previamente, de tamanho médio (70 mm de diâmetro longitudinal) foi usado como referência. Esse tubérculo foi colocado no início de cada esteira acionando-se o cronômetro de precisão. Usou-se como resultado final a média de cinco repetições, calculando-se a velocidade através da fórmula $\Delta \mathrm{s} / \Delta \mathrm{t}$ médio, sendo $\Delta \mathrm{s}$ o comprimento da esteira e $\Delta \mathrm{t}$ médio o tempo médio para o tubérculo percorrer esse comprimento.

A produção diária foi dimensionada baseando-se na média de trabalho men- 
sal de cada unidade. Para tanto, foram utilizadas as informações referentes à quantidade diária beneficiada e classificada, o horário de trabalho dos operários e o peso da saca de batatas, obtendo-se assim $\mathrm{kg}$ de tubérculos/operário/hora.

$\mathrm{Na}$ etapa de lavagem e limpeza foi medido o volume de água utilizada. A etapa de recebimento utiliza um grande volume de água, porém muito variável, portanto de difícil mensuração. Nesta avaliação foi utilizado um béquer com capacidade para $550 \mathrm{ml}$, para medir a vazão de água utilizada no processo por períodos fixos de tempo. Foram selecionados, ao acaso, bicos ou furos, dependendo da unidade de beneficiamento, para a medição do volume. Contou-se o número de furos ou bicos em toda a linha para obtenção do volume total de água utilizado.

O número de escovas utilizadas nas etapas de limpeza, polimento e secagem foi contado. Também determinou-se a origem do material das escovas de cada etapa: vegetal, animal e sintético. $\mathrm{Na}$ avaliação das medidas da rotação de operação no funcionamento das escovas nas etapas de lavagem, polimento e secagem determinou-se um ponto de referência e por meio de um cronômetro de precisão, utilizando-se um minuto como tempo padrão avaliou-se a rotação dessas esteiras, demarcando assim a contagem da freqüência, que foi determinada em rotações por minuto. Foram feitas cinco repetições para cada esteira, levando-se em consideração como resultado final a média das repetições.

A avaliação dos pontos de impacto (por queda) foi realizada utilizando-se a esfera instrumentada $(70 \mathrm{~mm})$, Techmark, Inc. Esfera instrumentada (Techmark, Inc., Lansing, EUA), é um equipamento plástico com registrador de aceleração, para a avaliação da magnitude de impactos em pontos de transferência em linhas de classificação de tomate (Sargent et al., 1992a), maçãs (Guyer et al., 1991; Sober et al., 1990), laranja (Miller \& Wagner, 1991), cebola (Timm et al., 1991), abacate, mamão e abacaxi (Timm \& Brown, 1991) e batata (Lopresti \& Thomson, 1998; Hyde et al., 1992). Para as avaliações mencionadas utilizou-se níveis de impactos

Tabela 1. Caracterização dimensional das unidades de beneficiamento e classificação de batatas (Dimensional characterization of the packing and classification lines of potatoes). Campinas, UNICAMP, 2004.

\begin{tabular}{|c|c|c|c|c|c|c|c|c|}
\hline \multirow{3}{*}{ Unidades** } & \multicolumn{8}{|c|}{ Comprimento da etapa $(\mathrm{m})$} \\
\hline & \multicolumn{8}{|c|}{ Etapas* } \\
\hline & 1 & 2 & 3 & 4 & 5 & 6 & 7 & Total \\
\hline$A$ & 8,00 & 2,20 & 19,90 & 13,00 & 2,95 & 6,30 & 1,60 & 53,95 \\
\hline B & 7,10 & 15,90 & 2,40 & 10,00 & 5,60 & 3,30 & 2,10 & 46,40 \\
\hline C & 9,10 & 2,50 & 10,40 & 11,70 & 6,00 & 2,60 & 2,00 & 44,30 \\
\hline D & 12,00 & 3,30 & 11,00 & 11,50 & 4,00 & 10,00 & 1,50 & 53,30 \\
\hline$E$ & 1,10 & 1,90 & 13,65 & 13,00 & 2,55 & 5,80 & 1,60 & 39,60 \\
\hline média & 7,46 & 5,16 & 11,53 & 9,93 & 4,24 & 5,6 & 1,76 & 45,68 \\
\hline
\end{tabular}

*Etapas: 1: Recebimento; 2: Limpeza 1; 3: Limpeza 2; 4: Secador; 5: Seleção; 6: Classificação; 7: Ensacamento. (Step 1: receiving; 2: cleaning 1; 3: cleaning 2; 4: Dryier 5: Selection; 6: classification; 7: packing).

medidos na aceleração máxima (AM) $\left(\mathrm{G}=9,81 \mathrm{~m} / \mathrm{s}^{2}\right)$ e mudanças na velocidade $(\Delta \mathrm{v})(\mathrm{m} / \mathrm{s}) . \Delta \mathrm{v}$ pode ser um indicativo da superfície de impacto, por exemplo, quanto mais baixa a velocidade, mais rígida e dura é a superfície de impacto. Todavia, velocidade é também positivamente correlacionada com a aceleração máxima, à medida que se aumenta a altura de queda, maior será a aceleração máxima e a velocidade (Sargent et al., 1992a).

A esfera instrumentada foi colocada na etapa de recebimento de cada linha, em funcionamento na sua capacidade normal, e foi movimentada juntamente com os tubérculos, seguindo o fluxo normal destes até a etapa de ensaque. $\mathrm{O}$ tempo de permanência da esfera em cada etapa, o tempo para completar o percurso e os pontos de transferência foram monitorados através do uso de um cronômetro de precisão. As medições foram repetidas oito vezes. Após os testes a esfera foi removida e os dados transferidos para o microcomputador. Os limites para medição do nível de impacto utilizados variaram de 15 a 500 G. Os dados obtidos nos pontos de transferência em cada avaliação foram correlacionados entre a aceleração máxima (AM) $\left(\mathrm{G}=9,81 \mathrm{~m} / \mathrm{s}^{2}\right)$ e mudanças na velocidade $(\Delta \mathrm{v})(\mathrm{m} / \mathrm{s})$ e apresentados através de gráficos. Para apresentação dos resultados foram utilizados os pontos coincidentes entre as unidades.

\section{RESULTADOS E DISCUSSÃO}

Todos os equipamentos nas cinco unidades estudadas eram nacionais, sen- do utilizado na construção chapa de aço carbono com espessura de 1,0-1,5 mm.

O comprimento do equipamento variou em $26,5 \%$, sendo o maior 53,95 metros e o menor equipamento 39,60 metros (Tabela 1). O equipamento mais longo era utilizado para beneficiamento de batata para indústria. Entre as etapas, as mais longas foram as referentes à limpeza e secagem. A etapa de limpeza era em geral dividida em duas, sendo que a primeira fase caracterizava-se por jatos de água de alta pressão e a segunda por uma maior quantidade de bicos e maior exposição do produto à lavagem. A secagem da batata em todos os galpões estudados era realizada utilizando-se altas temperaturas e percursos longos. A seleção e a classificação são etapas com menores comprimentos que as demais, sendo que nesta última a variação entre os valores deveu-se ao comprimento da grade classificadora. Quando ao diâmetro da grade de classificação utilizada verificou-se diversos valores. Os equipamentos das unidades A e E apresentaram diâmetro de $38 \mathrm{~mm}$; o da unidade B $43 \mathrm{~mm}$; o da unidade C 40 $\mathrm{mm}$; e o da unidade D apresentou três diâmetros: 40, 42 e 45 mm. O comprimento da etapa de ensaque foi semelhante em todos os galpões. O equipamento mais largo encontrado foi no galpão da unidade $\mathrm{A}$, com 1,80 metros e o menor valor foi observado na unidade $\mathrm{D}$, com 1,25 metros. A unidade B apresentou valor de 1,46 metros e as unidades $\mathrm{C}$ e E, 1,50 metros.

A medida da velocidade de operação das esteiras de abastecimento diferiu entre as unidades, sendo que nas 
Tabela 2. Produção diária das unidades de beneficiamento e classificação de batatas (Daily production of the packing and classification units of potato). Campinas, UNICAMP, 2004.

\begin{tabular}{lccccc}
\hline Unidades* $^{*}$ & $\begin{array}{c}\text { Número de } \\
\text { operários }\end{array}$ & $\begin{array}{c}\text { Peso da } \\
\text { saca (kg) }\end{array}$ & $\begin{array}{c}\text { Produção } \\
\text { (sacas/hora) }\end{array}$ & $\begin{array}{c}\text { Produção } \\
\text { diária } \\
\text { (sacas) }\end{array}$ & $\begin{array}{c}\text { Produtividade } \\
\text { (sacas/operário/hora) }\end{array}$ \\
\hline A & 12 & 50 & 300 & $3000-4000$ & 25 \\
B & 32 & 50 & 300 & $3000-4000$ & 10 \\
C & 30 & 50 & 400 & $4000-6000$ & 15 \\
D & 42 & 50 & 320 & $3000-4000$ & 7,6 \\
E & 25 & 50 & 300 & 1000 & 12 \\
\hline
\end{tabular}

*Unidades: A, B e C: Vargem Grande do Sul (SP); D: Itapetininga (SP); E: Divinolândia (SP).

Tabela 3. Consumo de água na etapa de lavagem em unidades que utilizam o sistema de bico aspersor, não sendo considerado o volume de água utilizado no recebimento. (Water use in the washing step, not considering the water volumen employed in the reception of units who employ aspersors). Campinas, UNICAMP, 2004.

\begin{tabular}{lcccc}
\hline \multicolumn{5}{c}{ Consumo de agua (sistema de bico aspersor) } \\
\hline Unidade & $\begin{array}{c}\text { Lavagem } \mathbf{1} \\
\text { (L/min) }\end{array}$ & $\begin{array}{c}\text { Lavagem 2 } \\
\text { (L/min) }\end{array}$ & Total de bicos & $\begin{array}{c}\text { Total } \\
\text { consumido } \\
\text { (L/hora) }\end{array}$ \\
\hline $\mathrm{A}$ & 480 & 162 & 138 & 38520 \\
$\mathrm{~B}$ & 162 & 94,5 & 140 & 15420 \\
\hline
\end{tabular}

*Unidades: A, B e C: Vargem Grande do Sul (SP); D: Itapetininga (SP); E: Divinolândia (SP).

Tabela 4. Consumo de água na etapa de lavagem, em unidades que utilizam o sistema de PVC perfurado, não sendo considerado o volume de água utilizado no recebimento (Water used in the washing step, not considering the water volumen employed in the reception of units who employ perforated PVC tubes). Campinas, UNICAMP, 2004.

\begin{tabular}{lcccc}
\hline \multicolumn{4}{c}{ Consumo de água (sistema de canos perfurados) } \\
\hline Unidade* $^{\text {Lavagem } 1}$ & $\begin{array}{c}\text { Lavagem 2 } \\
\text { (L/min) }\end{array}$ & Total de furos & $\begin{array}{c}\text { Total } \\
\text { consumido } \\
\text { (Uhora) }\end{array}$ \\
\hline $\mathrm{C}$ & 162 & 756 & 2295 & 55080 \\
$\mathrm{D}^{* *}$ & 140 & 2660 & 2610 & $168000^{*}$ \\
$\mathrm{E}$ & 108 & 2271 & 5310 & 142740 \\
\hline
\end{tabular}

"Unidade D possuía duas linhas para lavagem dos tubérculos, portanto os dados apresentados representam as duas esteiras de lavagem (The unit D had two potato washing lines; therefore the presented data represent two washing units).

unidades B e E não foi possível fazer as mensurações, devido ao difícil acesso a estas esteiras. A média calculada para esta etapa foi de $0,30 \mathrm{~m} . \mathrm{s}^{-1}$, variando de $0,17 \mathrm{~m} . \mathrm{s}^{-1}$ na unidade A a $0,53 \mathrm{~m} . \mathrm{s}^{-1}$ na unidade D. A unidade $\mathrm{C}$ apresentou velocidade de 0,21 m.s ${ }^{-1}$. Essa diferença pode ser proveniente da capacidade de operação, do comprimento e largura dos equipamentos desta etapa.

Na etapa de classificação a medida da velocidade das esteiras foi praticamente igual $\left(0,18 \mathrm{~m} \cdot \mathrm{s}^{-1}\right)$ para as cinco unidades avaliadas, o que pode ter sido devido à intensa utilização de mão-deobra no processo. Todavia, observou-se que a velocidade média de deslocamento dos tubérculos praticamente não variou entre as unidades, sendo $0,15 \mathrm{~m} . \mathrm{s}^{-1}$, o que pode estar relacionado ao volume dos tubérculos beneficiados e à rotação dos equipamentos.

A unidade A de beneficiamento e classificação de batatas possui número de trabalhadores menor que as demais, pois a sua produção destinava-se naquele momento ao processamento industrial, não sendo necessária uma seleção mais rigorosa para os padrões de classificação (Tabela 2). Essas unidades trabalham em épocas específicas do ano, por cerca de 10-14 horas diárias. Ob- serva-se que o comprimento das linhas (Tabela 1) não influenciou na produção diária das unidades, e que o número de funcionários foi independente deste comprimento, verificando-se então que fator gerencial pode ser uma importante ferramenta no rendimento de uma linha de beneficiamento.

Foi constatada variação no consumo de água entre as unidades devido à diferença no sistema utilizado para a lavagem dos tubérculos (Tabelas 3 e 4). As unidades A e B utilizam bico aspersor, enquanto que as unidades C, D e E utilizam cano de PVC perfurado Em todas as unidades foram observadas diferenças no funcionamento dos bicos aspersores utilizados e nos canos de PVC perfurados, os quais apresentavam freqüientes entupimentos. O consumo de água (L/hora) oscilou entre 15,4 e 168 mil L por hora o que pode ser devido à capacidade de operação de cada beneficiadora, à quantidade de bicos aspersores e perfurações e ao comprimento das etapas de lavagem em cada unidade. A unidade D utilizava duas linhas para a etapa de limpeza.

Com relação ao número de escovas notou-se que as cinco unidades de beneficiamento e classificação de batatas avaliadas possuíam na etapa de lavagem 2 maior número de escovas do que na etapa de lavagem 1 (Tabela 5). Quanto ao material, observou-se que escovas utilizadas nas etapas de lavagem eram compostas de cerdas com nylon cristal (diâmetro $0,35 \mathrm{~mm}$ ) e fibra de coco (material vegetal). Escovas compostas de origem animal (crina de cavalo) não foram encontradas nestas avaliações. Nas unidades B e D foram observadas, na etapa inicial de lavagem, a presença de cilindros metálicos para transporte dos tubérculos.

A rotação média para todas as unidades na etapa de lavagem foi de 157 rpm, oscilando de um mínimo de 112 e um máximo de 196 rpm, com variação de $75 \%$ (Tabela 6). Para a etapa de secagem, a rotação média foi de $122 \mathrm{rpm}$, oscilando de 68 a 210 rpm, variação de $308 \%$. Na unidade A, não foi possível calcular a rotação na etapa de secagem devido à incapacidade de visualização das esteiras. As diferenças observadas são devido aos equipamentos utilizados 
Tabela 5. Número de escovas utilizadas nas etapas de lavagem 1, lavagem 2 e secagem nas unidades de beneficiamento e classificação de batata (Number of brushes used in the washing steps 1 and 2 and drying step in the packing and classification units of potato). Campinas, UNICAMP, 2004.

\begin{tabular}{|c|c|c|c|c|c|c|c|c|c|c|c|c|c|c|c|}
\hline \multirow{3}{*}{ Material escovas } & \multicolumn{15}{|c|}{ Número de escovas } \\
\hline & \multicolumn{5}{|c|}{ Lavagem 1} & \multicolumn{5}{|c|}{ Lavagem 2} & \multicolumn{5}{|c|}{ Secagem } \\
\hline & A & B & C & D & $\mathbf{E}$ & A & B & $\mathrm{C}$ & D & $\mathrm{E}$ & A & B & C & $\mathbf{D}$ & $E$ \\
\hline Nylon & 10 & 6 & 5 & 0 & 13 & 0 & 0 & 0 & 0 & 55 & 0 & 0 & 0 & 0 & 1 \\
\hline PVC & 9 & 0 & 14 & 0 & 0 & 1 & 1 & 0 & 0 & 9 & 0 & 0 & 2 & 2 & 0 \\
\hline Fibra de coco & 0 & 0 & 0 & 0 & 0 & 75 & 107 & 94 & 140 & 42 & 1 & 0 & 0 & 0 & 0 \\
\hline Cilindro metálico & 0 & 9 & 0 & 23 & 0 & 0 & 0 & 0 & 0 & 0 & 0 & 0 & 0 & 0 & 0 \\
\hline Espuma & 0 & 0 & 0 & 0 & 0 & 0 & 0 & 0 & 0 & 0 & 12 & 20 & 15 & 13 & 18 \\
\hline Total & 19 & 15 & 19 & 23 & 13 & 76 & 108 & 94 & 140 & 106 & 13 & 20 & 17 & 15 & 19 \\
\hline
\end{tabular}

*Unidades: A, B e C: Vargem Grande do Sul (SP); D: Itapetininga (SP); E: Divinolândia (SP).

e as variações no abastecimento. Altas rotações podem causar eventuais danos físicos aos tubérculos. Comparando-se os resultados de rotação das escovas na lavagem com o volume de água gasto, notou-se que na unidade $\mathrm{B}$, em que a medida de rotação foi maior, houve o menor volume de água gasta, enquanto na unidade $\mathrm{D}$ em que a medida de rotação foi a menor, houve o maior volume de água gasto na lavagem dos tubérculos.

Por meio do uso da esfera instrumentada (70 mm), obtiveram-se dados de máxima aceleração $(\mathrm{G})$ e variação na velocidade $(\Delta \mathrm{v})$ para os impactos na linha de classificação e beneficiamento de batatas (Figuras 1, 2 e 3). Os pontos das linhas de classificação para batata que demonstraram maior $\mathrm{G}$ foram os de transferência (entrada no lavador e ensaque). Em três unidades (B, $\mathrm{C}$ e D) os maiores valores foram observados na etapa de lavagem (entrada do lavador), observando-se na unidade $\mathrm{C}$, $\mathrm{G}$ superior a $140 \mathrm{~m} / \mathrm{s}^{2}$. Na entrada do processo de secagem observa-se uma redução nos valores de $\mathrm{G}$ em todas as unidades, porém com crescente ascensão nos outros três pontos de transferência. A variação nos valores de G, entre as unidades para os pontos coincidentes, pode estar relacionada à velocidade de deslocamento, rotações das escovas, altura de queda e tipo de superfícies protetoras. Os menores valores de $G$ foram obtidos para Unidade $C$, na entrada do secador. Na saída do secador, o maior valor de $\mathrm{G}$ foi obtido na Unidade D (>80G) e o menor na unidade A (<60G). Para a saída da seleção, na unidade E obteve-se menor valor, inferior a $70 \mathrm{G}$, enquanto na unidade $\mathrm{A}$ obteve-se maior valor neste ponto de

Tabela 6. Medidas das rotações nas escovas (rpm) nas unidades de beneficiamento e classificação para batata (Rotation values on the brushes (rpm) in the packing and classification units of potato). Campinas, UNICAMP, 2004.

\begin{tabular}{ccc}
\hline \multicolumn{3}{c}{ Medida de rotação das escovas $(\mathrm{rpm})$} \\
\hline Unidade $^{*}$ & Lavagem & Secagem $^{* *}$ \\
\hline A & 160 & $\mathrm{NC}$ \\
B & 196 & 126 \\
C & 150 & 85 \\
D & 112 & 210 \\
E & 167 & 68 \\
\hline
\end{tabular}

Obs: NC = não consta; * Umidades A, B e C: Vargem Grande do Sul (SP); D: Itapetininga (SP); E: Divinolândia (SP); **Etapa de secagem utilizando-se escovas com espuma (Drying steps using brushes with foam)

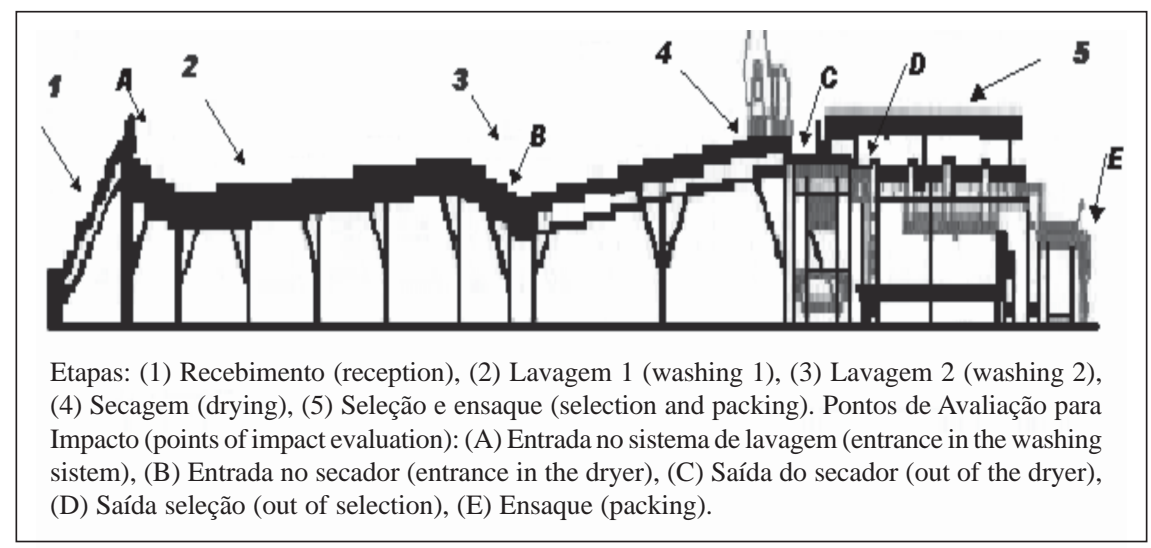

Figura 1. Desenho esquemático com as principais etapas e pontos de transferência avaliados para impacto em equipamento de beneficiamento e classificação de batatas (Chematic presentation presenting the main steps and transferring points evaluated on the impact of the equipment of the packing and classification units of potato). Campinas, UNICAMP, 2004.

transferência (>100G). Na etapa do ensaque as unidades A e C apresentaram os maiores valores e a $\mathrm{D}$ valores inferiores a $70 \mathrm{G}$.

Geralmente nas etapas iniciais são encontrados altos valores de impacto (Sargent et al., 1992a). Miller \& Wagner (1991) relatam que $80 \%$ dos impactos em linha de classificação para citrus variam entre $25-150 \mathrm{G}$ e são causados por quedas em superfícies rígidas de metal ou em uma camada de cobertura emborrachada muito fina. Todavia, na etapa de recebimento, foram observados valores de até 300G. Hyde et al. (1992) avaliaram linhas de beneficiamento e classificação para batata e observaram que maiores impactos são causados por quedas em superfícies rígidas.

Assim, verifica-se que os valores de G observados neste trabalho corroboram 
Tabela 7. Aceleração Máxima $(\mathrm{G})$ e velocidade $(\Delta \mathrm{v})$ em unidades de beneficiamento de batata (Maximal acdeleration $(\mathrm{G})$ and velocity $(\Delta \mathrm{v})$ in the packing and classification units of potato). Campinas, UNICAMP, 2004.

\begin{tabular}{|c|c|c|c|c|c|c|c|c|c|c|}
\hline \multirow{4}{*}{ Etapas } & \multicolumn{10}{|c|}{ Máxima aceleração $(\mathrm{G})$ e modificação velocidade $(\Delta v)$ para pontos coincidentes } \\
\hline & \multicolumn{10}{|c|}{ Unidades } \\
\hline & \multicolumn{2}{|c|}{ A } & \multicolumn{2}{|c|}{ B } & \multicolumn{2}{|c|}{ C } & \multicolumn{2}{|c|}{ D } & \multicolumn{2}{|c|}{$\mathrm{E}$} \\
\hline & $\mathbf{G}\left(\mathrm{m} / \mathbf{s}^{2}\right)$ & $\mathrm{V}(\mathrm{m} / \mathrm{s})$ & $\mathbf{G}\left(\mathrm{m} / \mathbf{s}^{2}\right)$ & $\mathrm{V}(\mathrm{m} / \mathrm{s})$ & $\mathbf{G}\left(\mathrm{m} / \mathrm{s}^{2}\right)$ & $\mathrm{V}(\mathrm{m} / \mathrm{s})$ & $\mathbf{G}\left(\mathrm{m} / \mathrm{s}^{2}\right)$ & $\mathrm{V}(\mathrm{m} / \mathrm{s})$ & $\mathrm{G}\left(\mathrm{m} / \mathrm{s}^{2}\right)$ & $\mathrm{V}(\mathrm{m} / \mathrm{s})$ \\
\hline Entrada lavador & 70,7 & 2,74 & 133,5 & 2,89 & 144,7 & 2,36 & 129,5 & 1,80 & 93,55 & 1,75 \\
\hline Entrada secador & 64,8 & 1,70 & 80,5 & 1,30 & 29,8 & 0,75 & 50,8 & 1,00 & 40,64 & 0,89 \\
\hline Saída secador & 57,7 & 1,35 & 74,6 & 1,68 & 88,8 & 2,20 & 76,7 & 1,20 & 92,24 & 2,09 \\
\hline Saída da seleção & 107,4 & 1,93 & 101,9 & 2,11 & 78,5 & 1,50 & 93,4 & 2,40 & 67,18 & 1,37 \\
\hline Ensaque & 122,4 & 2,58 & 103,5 & 2,31 & 122,3 & 2,32 & 95,4 & 1,60 & 107,61 & 1,88 \\
\hline
\end{tabular}

*Unidades: A, B e C: Vargem Grande do Sul (SP); D: Itapetininga (SP); E: Divinolândia (SP).

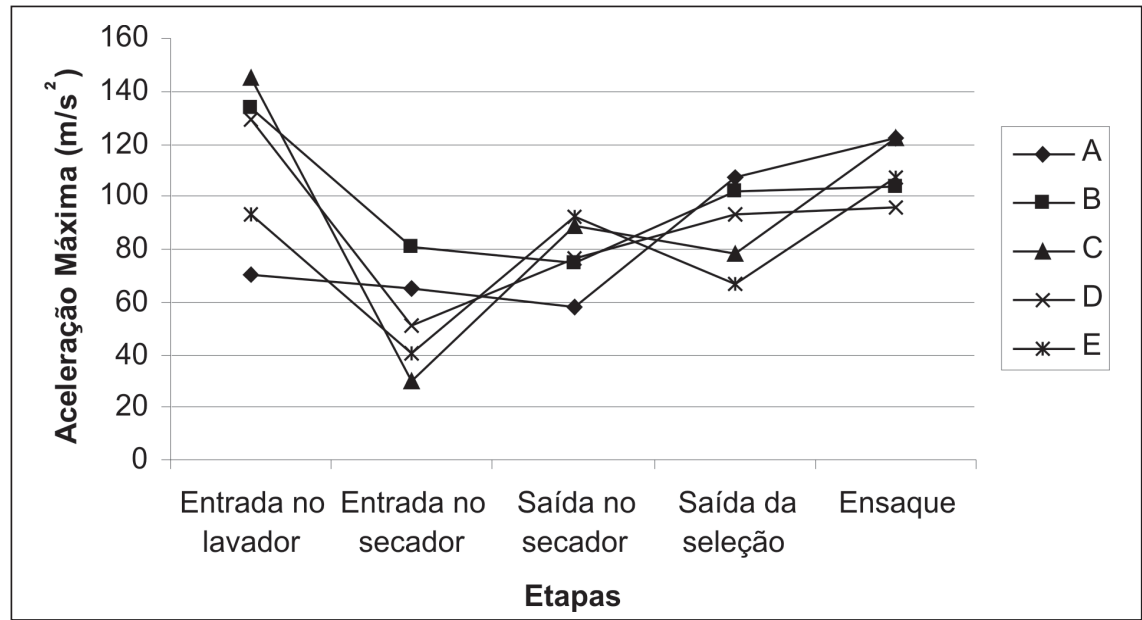

Figura 2. Aceleração máxima $\left(\mathrm{m} / \mathrm{s}^{2}\right)$ para pontos coincidentes nas cinco unidades de beneficiamento e classificação de batatas (maximum acceleration $\left(\mathrm{m} / \mathrm{s}^{2}\right)$ on coincident points of the five packing and classifying units of potato). Campinas, UNICAMP, 2004.

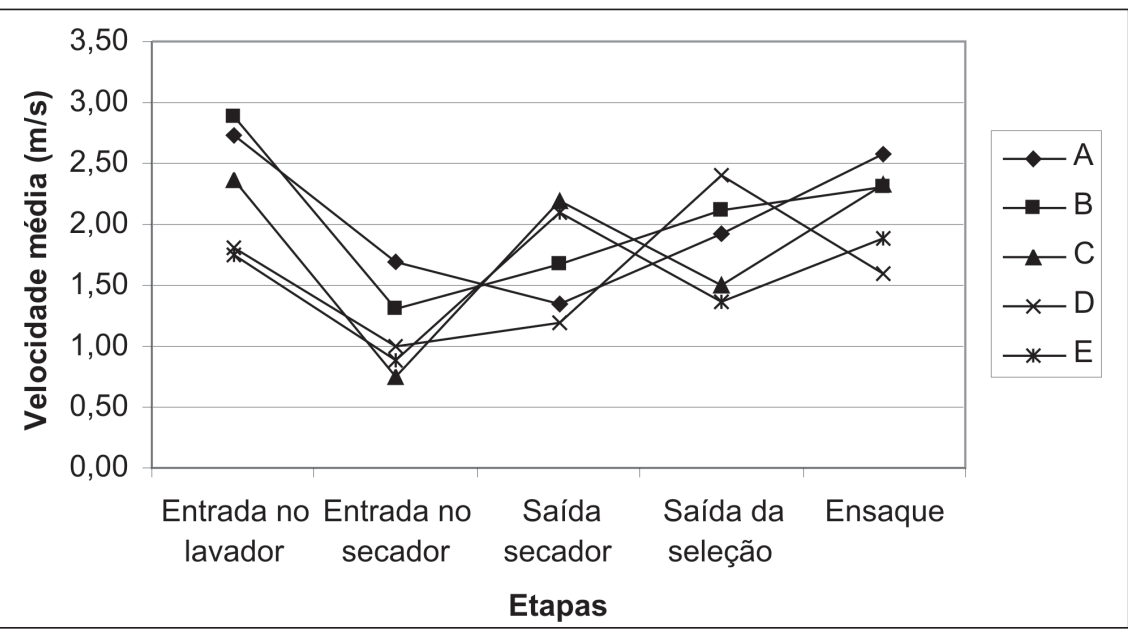

Figura 3. Velocidade média $(\mathrm{m} / \mathrm{s})$ para pontos coincidentes nas cinco unidades de beneficiamento e classificação de batata (Average speed $(\mathrm{m} / \mathrm{s})$ for coincident points of the five packing and classifying units of potato). Campinas, UNICAMP, 2004.

os autores supracitados. Timm \& Brown (1991) relataram uma diminuição no impacto em linhas de classificação de abacate, mamão e abacaxi, quando da utilização de protetores emborrachados. Sargent et al. (1992a) também relataram que utilizando se de menores pontos de queda e que modificações em alguns pontos da linha de classificação de tomates de mesa, por meio da utilização de protetores de superfície, proporcionaram redução em até $50 \%$ na pressão de impacto, com conseqüente diminuição nos danos físicos.

Quanto a $\Delta v$ observa-se que existe uma similaridade entre os gráficos apresentados (Figuras 2 e 3 ). Isto pode ser explicado pela correlação positiva obtida entre o $\Delta v$ e a $G$ (Tabela 7), já que para uma dada superfície o aumento da altura de queda aumentará tanto a aceleração como a velocidade (Sargent $e t$ al., 1992a).

Com os dados obtidos pode-se caracterizar as linhas de beneficiamento e classificação utilizadas de batatas e observar os seus pontos críticos os quais podem ser utilizados para dimensionamento de novos equipamentos e intervenções nas unidades em funcionamento, principalmente quanto aos pontos de impacto, os quais foram localizados em todos os equipamentos de classificação e beneficiamento de batatas.

Conclui-se, portanto, que não existe a necessidade de linhas extensas e grandes quantidades de água, e sim de que ocorra a otimização do uso dos recursos e equipamentos. Uma linha ideal para funcionamento, tem como características desejadas utilizar o mínimo de água em rotações, as quais não causem danos físicos ao produto. Nos pontos de transferência a magnitude de impacto pode ser minimizada a partir do uso de protetores de superfície e pela diminuição na altura da queda. Estudos futuros podem ser conduzidos com a finalidade de se observar a relação entre os impactos sofridos e perdas pós-colheita, em especial causadas pela incidência de doenças. 


\section{AGRADECIMENTOS}

Os autores agradecem à Fundação de Amparo a Pesquisa do Estado de São Paulo, FAPESP e à Associação Brasileira da Batata, ABBA.

\section{REFERÊNCIAS}

FNP CONSULTORIA \& COMERCIO. 2004 AGRIANUAL 2005 - Anuário Estatístico da Agricultura Brasileira. São Paulo: 560p.

CEAGESP. 2001. Classificação da Batata "in natura". Programa Brasileiro para a Melhoria dos Padrões Comerciais e Embalagens de Hortigranjeiros, $4 \mathrm{p}$.

EXPIDO J; BUENO J; VAN CANNEYT T. 2005 Impact detection in potato handling lines with sensors based on triaxial accelerometers. Acta Horticulturae 682: 1125-1131.

FINGER FL; FONTES PCR. 1999. Manejo póscolheita da batata. Informe Agropecuário 20: 105-111.

GUYER DE; SCHULTE NL; TIMM EJ; BROWN GK. 1991. Minimize apple bruising in the packingline. Tree Fruit Postharvest Journal 2: 14-20.

HENZ GP; BRUNE S. 2004. Redução de perdas pós-colheita em batata para consumo. Brasília: Embrapa, 10 p. (Circular Técnica 34).
HYDE GM; ZHANG W. 1992. Apple bruising research update: packingline impact evaluations. Tree Fruit Postharvest Journal August 3: 12-15.

HYDE GM; BROWN GK; TIMM RJ; ZHANG W. 1992. Instrumented sphere evaluation of potato packing line impacts. Transactions of the ASAE 35: 65-69.

JOBLING J. 2000. Potatoes: handle with care. Good Fruit and Vegetables Magazine 11: 3435.

LOPRESTI J; THOMSON G. 1998. Instrumented sphere assessment of seed potato packing lines. ExpHORT 2000 Report. Institute for Horticultural Development Knoxfield, Victoria, Australia. Disponível em: <http:// www.nre.vic.gov.au/agvic/ihd/r\&d/doc095.htm\#pagetop>. Acesso: 20.02.2004.

MILLER WM; WAGNER C. 1991. Florida citrus packing line studies with an instrumented sphere. Applied Engineering in Agriculture 7: 577-581.

MORETTI CL; SARGENT SA. 2000. Alteração de sabor e aroma em tomates causada por impacto. Scientia Agrícola 57: 385-388

MOHSENIN NN. 1970. Physical properties of plant and animal materials. Vol. I Gordon e Beach Science Publishers: New York, p.401430.

RESENDE LMA; MASCARENHAS MHT; PAIVA BM. 1999. Aspectos econômicos da produção e comercialização de batata. Informe Agropecuário 120: 9-15.
SARGENT SA; RITENOUR MA; BRECHT JK. 1999. Handling, Cooling and Sanitation Techniques for Maintaining Postharvest Quality. Horticultural Sciences Department HS719, Florida Cooperative Extension Service, Institute of Food and Agricultural Sciences, University of Florida.

SARGENT SA; BRECHT JK; ZOELLNER JJ. 1992a. Instrumented sphere impact analyses of tomato and bell pepper packing lines. Applied engineering in agriculture 8: 76-83.

SARGENT SA; BRECHT JK; ZOELLNER JJ. $1992 b$. Sensitivity of tomatoes at mature-green and breaker ripeness stages to internal bruising. Journal of the American Society for Horticultural Science 117: 119-123.

SOBER SS; ZAPP HR; BROWN GK. 1990. Simulated packing line impacts for apple bruise prediction. Transactions of the ASAE 33: 629-636.

TIM EJ; BROWN GK. 1991. Impacts recorded on avocado, papaya, and pineapple packing lines. Applied engineering in Agriculture 7: 418-422.

TIM EJ; BROWN GK; BROOK RC; SCHULTE NL; BURTON CL. 1991. Impact bruise estimates for onion packing lines. Applied engineering in Agriculture 7: 571-576. 